\title{
ĐÁNH GIÁ KẾT QUẢ ĐIỀU TRI PHẪU THUẬT U HẬU NHÃN CẦU TẠI BỆNH VIỆN K
}

\section{TÓM TẮT}

Mục tiêu: Đánh giá kết quả điều trị phẫu thuật u hậu nhãan cầu. Đối tượng và phương pháp nghiên cứu: nghiên cứu cắt ngang, hồi cứu và tiến cứu, gồm 30 bênh nhân u hậu nhãn câuu được chẩn đoán, điều trị phâuu thuật tại khoa Ngoại Thần Kinh - bệnh viện K từ 01/2017 đến 06/2021. Kết quả: Tỷ lệ nam/nữ là $1,14 / 1$; tuổi trung bình là $37,8 \pm 22,6$ (4-71 tuổi). Triệu chứng lâm sàng thường hay gặp nhất là lồi măt (90\%), đau mắt $(86,7 \%)$, giảm thị lực $(76,7 \%)$. Khối u lành tính $(43,4 \%)$, u ác tính $(56,7 \%)$; trong đó hay gặp nhất là u màng não $(23,3 \%)$, sarcoma cơ vân thể bào thai $(13,3 \%)$, carcinoma không sừng hóa xâm nhâp $(10 \%)$. Kết quả lấy toàn bô u và gần toàn bộ là $46,7 \%$ và $33,3 \%$. Không có trường hợp nào tử vong, chảy máu do phẫu thuật. Kết quả khám lại hiện tại: Có $8 / 30(26,7 \%)$ bệnh nhần tử vong, trung bình 9,0 04,3 tháng, các loại giải phẫu bệnh (Carcinom không sừng hóa xâm nhập; Sarcoma (cơ vân thể hốc, xương, cơ vân thể bào thai, sun trung mô, xơ bì lồi); Carcinom biểu bì nhày độ cao). U tiến triển, tái phát: có $6 / 30$ $(20 \%)$, trung bình $9,0 \pm 4,3$ tháng, các loại giải phấu bệnh (Hemangiopericytome malin độ III, Sarcoma (cơ vẩn thể hốc, xương, cơ vân thể bào thai, xớ bì lồi), Carcinom không sừng hóa xâm nhập). Còn u tồn dư, u lành tính, không tiến triển: có $9 / 30$ (30\%), trung bình $15,67 \pm 12,7$ tháng, các loại giải phẩu bệnh (u màng não, loạn sản xơ xương, u mạch thể tĩnh mạch, giả u - viêm mạn). Không còn u, u lành tính: có 4/30 $(13,3 \%)$, trung bình $19,25 \pm 8,9$ tháng, các loại giải phẫu bệnh (Swhannoma, u màng não). Kết Iuận: Phẫu thuật là phương pháp hiệu quả để chẩn đoán và điều trị các u hậu nhãn cầu. Tỉ lệ lấy toàn bộ u và gần toàn bộ là $46,7 \%$ và $33,3 \%$, tỉ iệ biến chứng sau mổ thấp (Ćó 4 ca chiếm 13,33\% trường hợp nhiêm trùng tại chố hốc mắt. Không có biến chứng chảy máu nội nhãn hay máu tụ nội sọ, rò dịch não tủy, tràn khí).

Từ khóa: U hậu nhãan cầu, u hốc mắt, phẫu thuật qua sọ, mở trần hốc mắt.

\section{SUMMARY}

\section{RESULTS OF SURGICAL TREATMENT OF ORBITAL TUMORS AT K HOSPITAL}

Objective: Evaluation of treatment of patients with orbital tumors in $\mathrm{K}$ national the combination of radiation therapy and/or post-operative chemicals. Methods: Cross-sectional, retrospective and prospective study, 30 patients with orbital tumor is diagnosed and operated at the Department of

\section{*Bênh viên $K$}

Chịu trách nhiệm chính: Nguyễn Đức Liên

Email: drduclien@gmail.com

Ngày nhận bài: 10.8 .2021

Ngày phản biện khoa học: 7.10.2021

Ngày duyệt bài: 15.10.2021

\section{Nguyễn Đức Liên*, Hoàng Văn Luyện*}

Neurosurgery - K national Hospital from $1 / 2017$ to $6 / 2021$. Results: The ratio male/female $=1,14 / 1$. Mean age of the patient was $37.8 \pm 22.6$ years (age range 4 - 71 years). The most common presenting symptoms were proptosis in 27 patients $(90 \%)$, eye pain $86,7 \%$; vision loss $76,7 \%$. There were $17(56,7 \%)$ patients with malignant tumors, $13(43,4 \%)$ with benign tumors. The most common lesion types were meningioma $(23.3 \%)$, embryonic rhabdomyosarcoma $(13.3 \%)$, invasive nonkeratinizing carcinoma (10\%). Total resection was achieved in 14 patiens $(46,7 \%)$ while subtotal resection was 33,3\%. No one died, intracranial hematoma in this study. Current follow-up results: $8 / 30(26.7 \%)$ patients died, average $9.0 \pm 4.3$ months, pathologic types (non-keratinizing carcinoma; Skeletal muscle sarcoma, bone sarcoma, embryonic rhabdomyosarcoma, chondrosarcoma, scleroderma sarcoma, high-grade epidermal carcinoma.Tumor progression, recurrence: $6 / 30(20 \%)$, average $9.0 \pm$ 4.3 months, pathologic types (Hemangiopericytome malin grade III, Sarcoma (skeletal muscle, bone, embryonic rhabdomyosarcoma, scleroderma), non keratinizing carcinoma). Residual tumors, benign tumors, no progression: $9 / 30(30 \%)$, average $15.67 \pm$ 12.7 months, pathologic types (meningioma, fibrous dysplasia, venous vascular tumor, pseudotumor chronic inflammation). No tumor, benign tumor: 4/30 $(13.3 \%)$, average $19.25 \pm 8.9$ months, pathological types (Swhannoma, meningioma). Conclusion: Surgery is an effective approach for the management of orbital tumors. Total resection was achieved in 14 patiens $(46,7 \%)$ while subtotal resection was $33,3 \%$. The rate of postoperative complications is low (There were 4 cases $(13,33 \%)$ of infection at the eye socket. There was not intraorbital or intracranial hematoma, cerebrospinal fluid leak, pneumonia intracranial).

Keywords: Retrobulbar tumor, orbital tumor, transcranial approaches, transcranial superior orbitotomy.

\section{I. ĐĂT VẤN ĐỀ}

U hậu nhãn cầu là một bệnh lý hiếm gặp, theo Hội ung thư Hoa Kỳ thì tần suất mắc bệnh chỉ khoảng 1/100000 người [7]. Do hốc mắt là vùng có thể tích nhỏ hẹp, cấu trúc giải phẫu phức tạp, thương tổn bệnh lý rất đa dạng và khó về mặt chẩn đoán cũng như điều trị do triệu chứng đa dạng, phức tạp và không đặc hiệu nển thường phân biệt với bệnh lý khác ở mắt và các cơ quan lân cận. U hậu nhãn cầu nguyên phát chiếm $70 \%$, từ tổ chức kế cận khoảng $23 \%$, di căn từ các tổ chức xa khác chiếm $4 \%$, từ các bệnh hệ thống chiếm 3\%[2],[6].

Về chẩn đoán: với sự phát triển của chụp cắt lớp vi tính, chụp cộng hưởng từ đã giúp chẩn 
đoán chính xác vị trí u, định hướng chẩn đoán, định hướng chiến lược điều trị bệnh. Về điều trị, với tiến bộ trong vi phẫu thần kinh, phẫu thuật nội soi và hệ thống định vị thần kinh, dao hút u bằng siêu âm đã giúp tiếp cận các loại khối u hậu nhãn cầu một cách chính xác và an toàn. Phẫu thuật là lựa chọn đầu tiên nhằm mục đích chẩn đoán giải phẫu bệnh, giải quyết tổn thương. Có 3 đường tiếp cận: đường trực tiếp vào hốc mắt, đường qua sọ trần và thành bên hốc mắt và đường mổ nội soi qua mũi để tiếp cận tổn thương thành trong hốc mắt, một số trường hợp có thể phối hợp các đường mổ trên. Chọn lựa đường mổ được làm chủ yếu dựa trên vị trí, loại tổn thương, mức độ lan tỏa của u cũng như mục đích của phầu thuật $[1],[5],[6]$.

Tại bệnh viện $K$, có đủ các chuyên khoa để điều trị cho bệnh lý u hậu nhãn cầu: chuyên khoa ngoại thần kinh, xạ trị, hóa trị, triển khai thường quy từ năm 2017. Vî̀ vậy, chúng tôi tiến hành đề tài: "Đánh giá kết quả điêu trị phẫu thuật u hậu nhãn cầu tại bệnh viện $\mathrm{K}^{\prime \prime}$ là cần thiết, nhằm phục vụ cổng tác điều trị cũng như tiên lượng bệnh lý này.

\section{II. ĐỐI TƯỢNG VÀ PHƯƠNG PHÁP NGHIÊN CỨU}

Tiêu chuâin lựa chon: gồm các bệnh nhân được chẩn đoán và phẫu thuật u hậu nhãn cầu tại bệnh viện $\mathrm{K}$ từ 01/2017 đến 06/2021; được chụp phim cộng hưởng từ hoặc cắt lớp vi tính ổ mắt trước mổ.

Tiêu chuẩn loại trừ: các tổn thương hậu nhãn cầu cả hai bên mắt, tình trạng nhiếm trùng, có bệnh lý toàn thân nặng (suy tim, suy thận, COPD...)

Phương pháp nghiên cứu: nghiên cứu cắt ngang, hồi cứu và tiến cứu.

Nội dung nghiên cứu: Gồm các thông tin cá nhân: tuối, giới; các triệu chứng lâm sàng ; Vị trí của u xác định trên CT hoặc MRI: u hậu nhãn câu được chia theo tác giả Boari (2011):
(1) u ở đỉnh ở mắt (khi khối u nằm ở phía sau mặt phẳng của cánh lớn xương bướm (lát cắt Axial - hình 1)),

(2) u ở giữa đỉnh ổ mắt và nhãn cầ; ở vùng này lại được chia thành 3 vùng tương quan với thần kinh thị: trên ngoài, trên trong, vùng dưới (theo mặt phẳng coronal, mỗi vùng là $120^{\circ}$ như hình 1).

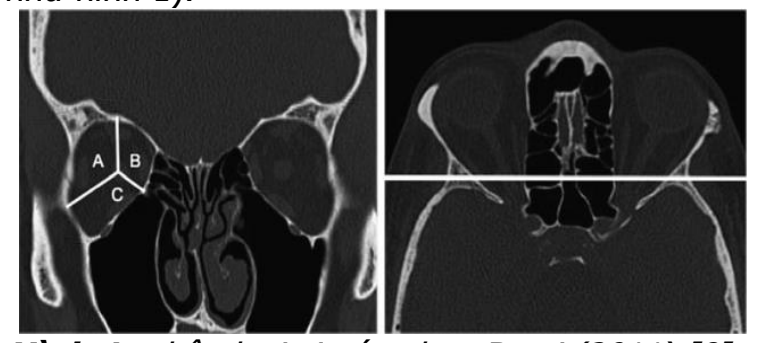

Hình 1: phân loại vi trí u theo Boari (2011) [8]

Mức độ lấy u: Được chia làm 4 mức độ dựa theo Margalit $N$ có biến đổi [4] Lấy toàn bộ u (lấy hết $\mathrm{u}$ về đại thể kiểm tra bằng $\mathrm{CT}$ hoặc MRI sau mổ); lấy gần hết u ( $\geq 90 \%$ thể tích u); lây u bán phần (<90\% thể tích $u)$; sinh thiết u

Đánh giá kết quả gồm: biến chứng và kết quả sớm sau mổ được đánh giá tại thời điểm ra viện, và kết quả khám lại sau 03 tháng và hiện tại.

\section{KẾT QUẢ NGHIÊN CỨU}

Giới: Tỷ lệ mắc bệnh nam và nữ lần lượt là: $53,3 \%$ và $46,7 \%$.

Tuổi: Tuổi nhỏ nhất 4 tuổi, lớn nhất 71 tuổi; Trung bình $37,8 \pm 22,6$.

Diễn biến bệnh: Lý do đến viện chủ yếu là lồi mắt $(90 \%)$, đau mắt $(86,7 \%)$, giảm thị lực $(76,7 \%)$, liệt dây thần kinh vận nhãn $9 / 30$ $(30 \%)$, nhìn đôi $5 / 30(16,7 \%)$. Thời gian khởi phát bệnh đến nhập viện điều trị trung bình 6,98 $\pm 2,5$ tháng.

Vị trí u: Vị trí hay găp nhất là tổn thương toàn bô hốc mắt $26,7 \%$; u ở đỉnh hốc mắt $(23,3 \%)$, ở phía trên ngoài $(20 \%)$, thấp nhất là trên trong $(6,7 \%)$.

Bảng 1: Phân bố vị trí của u hậu nhãn câu

\begin{tabular}{|c|c|c|c|c|}
\hline \multirow[b]{2}{*}{ Vị trí } & \multicolumn{3}{|c|}{ Đường mổ } & \multirow[b]{2}{*}{ n, \% } \\
\hline & $\begin{array}{l}\text { Mở nắp so- } \\
\text { trân ổ mắt }\end{array}$ & $\begin{array}{l}\text { Đường ổ mắt tự } \\
\text { nhiên }\end{array}$ & $\begin{array}{l}\text { Nội soi qua } \\
\text { mũi }\end{array}$ & \\
\hline Trên trong & 2 & 0 & 0 & $2(6,7 \%)$ \\
\hline Đỉnh hốc mắt & 4 & 1 & 2 & $7(23,3 \%)$ \\
\hline Bao bọc thân kinh thị & 4 & 0 & 0 & $4(13,3 \%)$ \\
\hline Trên ngoài & 5 & 1 & 0 & $6(20 \%)$ \\
\hline Dưới trong & 2 & 0 & 1 & $3(10 \%)$ \\
\hline Toàn bộ hốc mắt & 4 & 4 & 0 & $8(26,7 \%)$ \\
\hline Tổng số & $21(70 \%)$ & $6(20 \%)$ & $3(10 \%)$ & $30(100 \%)$ \\
\hline
\end{tabular}


Bảng 2. Kêt quả giải phẫu bệnh, khả năng phẫu thuật $(n=30)$

\begin{tabular}{|c|c|c|c|c|c|}
\hline \multirow{2}{*}{\multicolumn{2}{|c|}{ Kết quả giải phẫu bênhh }} & \multicolumn{3}{|c|}{ Phấu thuật } & \multirow[b]{2}{*}{ Sinh thiết } \\
\hline & & Lấy toàn & $\begin{array}{l}\text { Lấy gần } \\
\text { hết }\end{array}$ & Lấy u bán & \\
\hline \multirow{7}{*}{ Ác tính } & $\begin{array}{l}\text { Sarcoma (cơ vân thế bào thai, xơ bì lồi, } \\
\text { xương, mach, cơ vân thể hốc, sun trung mô) }\end{array}$ &.- & 3 & 0 & 0 \\
\hline & Carcinom biếu bì nhày độ cao & 0 & 1 & 0 & 0 \\
\hline & Carcinom không sừng hóa xầm nhâp & 0 & 0 & 2 & 1 \\
\hline & Melanoma & 1 & 0 & 0 & 0 \\
\hline & Hemangiopericytome malin, độ III & 1 & 0 & 0 & 0 \\
\hline & U lympho non - Hodgkin TB B & 0 & 1 & 0 & 0 \\
\hline & K biếu mô TB đáy & 1 & 0 & 0 & 0 \\
\hline \multirow{6}{*}{$\begin{array}{l}\text { Lành } \\
\text { tính }\end{array}$} & U màng não & 3 & 4 & 0 & 0 \\
\hline & Giả u, viêm & 0 & 0 & 0 & 3 \\
\hline & Loạn sản xơ xương & 1 & 0 & 0 & 0 \\
\hline & Schwannoma & 1 & 0 & 0 & 0 \\
\hline & U mạch thế tĩnh mạch & 0 & 1 & 0 & 0 \\
\hline & Tổng & $\begin{array}{c}14 \\
(46,7 \%)\end{array}$ & $\begin{array}{c}10 \\
(33,3 \%)\end{array}$ & $\begin{array}{c}2 \\
(6,7 \%)\end{array}$ & $\begin{array}{c}4 \\
(13,3 \%)\end{array}$ \\
\hline
\end{tabular}

Kết quả ngay sau mổ (thời điểm ra viện): Tử vong $0 \%$, nhiễm trùng tại chỗ $4 \mathrm{ca}(13,33 \%)$; không có ca nào chảy máu, rò dịch não tủy, tràn khí hay mổ lại.

Bảng 3. Điều trị bổ trợ sau phẫu thuật

\begin{tabular}{|c|c|c|}
\hline $\begin{array}{c}\text { Điêuu trị bố trợ sau phâu } \\
\text { thuật }\end{array}$ & $\mathbf{n}=\mathbf{3 0}$ & $\mathbf{\%}$ \\
\hline Hóa trị & 1 & 3,4 \\
\hline Xạ trị & 7 & 23,3 \\
\hline Hóa xạ trị & 7 & 23,3 \\
\hline Không cân điều trị bố trợ & 15 & 50 \\
\hline
\end{tabular}

Kết quả khám lại: thời gian (ngắn nhất 03 tháng, dài nhất 48 tháng, trung bình 16,13 \pm 11,5 tháng); Tỷ lệ chụp CT, MRI kiểm tra ở thời điểm khám lại sau 03 tháng chiếm $100 \%$ và hiện tại chiếm 26/30 (86,7\%).
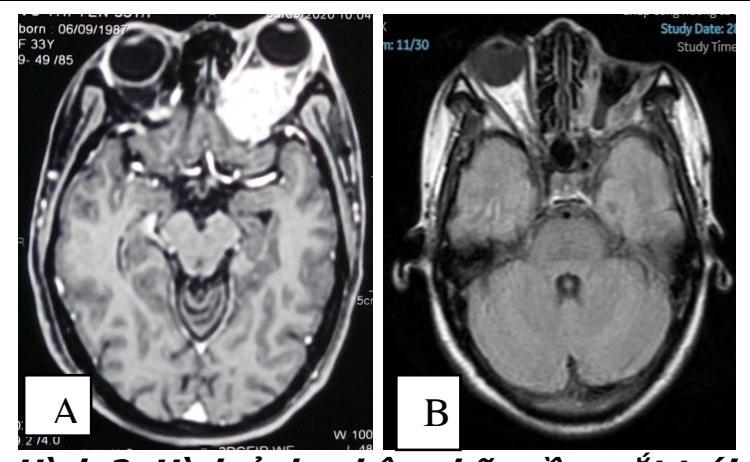

Hình 2: Hình ảnh u hậu nhãn cầu mắt trái.

(A) MRI trước mổ; (B) MRI sau mố.

Giải phẫu bệnh: U hắc tố ác tính. (Nguồn: BN VŨ $T H I$ Y.)

Bảng 4. Kêt quả khám lại-giải phẫu bệnh

\begin{tabular}{|c|c|c|c|c|c|c|}
\hline \multirow{2}{*}{$\begin{array}{l}\text { Kết quả } \\
\text { khám lại }\end{array}$} & \multirow{2}{*}{\multicolumn{2}{|c|}{\begin{tabular}{|c|c|} 
Số & Tỷ lệ \\
Iượng $(\%)$
\end{tabular}}} & \multicolumn{3}{|c|}{ Thời gian (tháng) } & \multirow[b]{2}{*}{ Các loại GPB } \\
\hline & & & $\begin{array}{c}\text { Ngắn } \\
\text { nhất }\end{array}$ & nhất & $\begin{array}{c}\text { Trung } \\
\text { bình }\end{array}$ & \\
\hline Tử vong & $8 / 30$ & 26,7 & 3 & 17 & $\begin{array}{c}9,0 \pm \\
4,3\end{array}$ & $\begin{array}{l}\text { Carcinom không sừng hóa xâm nhâap } \\
\text { Sarcoma (cơ vân thể hốc, xương, cơ vân thê } \\
\text { bào thai, sụn trung mô, xơ bì lồi), Carcinom } \\
\text { biểu bì nhày độ cao. }\end{array}$ \\
\hline $\begin{array}{l}\text { U tiến triển \& } \\
\text { tái phát }\end{array}$ & $6 / 30$ & 20 & 5 & 48 & $\begin{array}{l}18,17 \\
\pm 15,5\end{array}$ & $\begin{array}{c}\text { Hemangiopericytome malin độ III, Sarcoma } \\
\text { cơ vân thể hốc, sarcoma xương, Sarcoma co } \\
\text { vân thể bào thai, Carcinom không sững hóa } \\
\text { xâm nhập, Sarcoma xơ bì lồi. }\end{array}$ \\
\hline $\begin{array}{c}\text { U tồn dư, } \\
\text { u lành tính \& } \\
\text { không tiến triển }\end{array}$ & $9 / 30$ & 30 & 3 & 45 & $\begin{array}{c}15,67 \pm \\
12,7\end{array}$ & $\begin{array}{l}\text { U màng não, loạn sản xơ xương, u mạch thê } \\
\text { tînh mạch, giả u - viêm mạn }\end{array}$ \\
\hline $\begin{array}{l}\text { Không còn u, u } \\
\text { lành tính }\end{array}$ & $4 / 30$ & 13,3 & 11 & 27 & $\begin{array}{c}19,25 \pm \\
8,9\end{array}$ & Swhannoma, u màng não. \\
\hline
\end{tabular}

Triệu chứng lâm sàng khi khám lại: lồi mắt 6/30 (20\%), đau hậu nhãn cầu 4/30 (13,3\%), liệt dây thần kinh vận nhãn 3/30 (10\%). 


\section{BÀN LUÂN}

Trong nghiên cứu của chúng tôi tuổi trung bình là $37,8 \pm 22,6$ tuổi $(4-71)$, không có sự khác biệt về giới. Điều này phù hợp với nghiên cứu trong và ngoài nước là u hậu nhãn cầu thường gặp ở độ tuổi trung niên và sự khác biệt ở hai giới là không lớn. Theo nghiên cứu [2], [6] u hậu nhãn cầu ở trẻ em thường gặp là u tế bào đêm của thần kinh thi, ung thư cơ vân, trong đó người lớn thường thấy u màng não, $u$ tế bào Schwann... Trong nghiên cứu của chúng tôi không có sự khác biệt về mắt bệnh học ở từng nhóm tuổi, điều này do mẩu nghiên cứu của chúng tôi chưa đủ lớn.

Dấu hiệu rất thường gặp nhất của u hậu nhãn cầu là dấu hiệu lồi mắt. Trong nghiên cứu của chúng tôi, lî̀i mắt là dấu hiệu chủ yếu ( $90 \%$ các trường hợp). Đánh giá hướng lồi, lệch của nhãn câu cho chúng ta dự đoán về bệnh học của khối u. Ví như u dây thần kinh thị thường đẩy nhãn cầu theo trục dọc ra trước. Kết quả này cao hơn với các nghiên cứu nước ngoài [1], [6]. Triệu chứng đau thường gặp ở những trương hợp u di căn, u ác tính tiến triển nhanh. Đau trong u hậu nhãn cầu thường khu trú, hằng định, đau nhiều về đêm. Những u lành tính thường ít gây đau hơn mặc dù người bệnh có thể cảm giác căng tức vùng mắt. Nghiên cứu trên cho thấy triệu chứng đau mắt xuất hiện chiếm $86,7 \%$ cao hởn các nghiên cứu [2], [6], [7]. Giảm thị lực là một triệu chứng rất quan trọng chẩn đoán phân biệt những khối u nguyên phát ảnh hưởng dây thần kinh thị. Khối u màng não hay glioma dây thần kinh thị thường gây giảm thị lực đáng kể, trong khi các khối u ngoài trục cơ vận nhãn chỉ gây ảnh hưởng thị lực khi khối u phát triển choán chỗ đủ lớn gây chèn ép thần kinh thị giác [5]. Nghiên cứu của chúng tôi, triệu chứng giảm thị lực chiếm $76,7 \%$. Các triệu chứng khác tần suất ít hơn có thể gây nên tình trạng khó chịu, ảnh hưởng chức năng cho bệnh nhân. Như: sung huyêt, sụp mi, sưng, ... do khối u gây nên [2],[6], [7].

Thời gian khởi phát bệnh đến nhập viện điều trị trung bình $6,98 \pm 2,5$ tháng. Kết quả cũng như các nghiên cứu [2 ], [6].

Vị trí khối u giúp lựa chọn đường mổ sao cho phù hợp.Trong đó, vị trí tổn thương toàn bộ hốc mắt $26,7 \%$; u ở đỉnh hốc mắt (23,3\%), ở phía trên ngoài $(20 \%)$, thấp nhất là trên trong $(6,7 \%)$. Đường kính u trên MRI trung bình là $35,1 \pm 13,6 \mathrm{~mm}$; kích thước lớn nhất 7,8cm nằm ở vị trí hậu nhãn cầu nên gây ra nhiều triệu chứng, khó khăn về phẫu thuật, nhất là chọn lựa đường mổ. Việc đánh giá cấu trúc khối u trền chẩn đoán hình ảnh, tiên lượng giải phẫu bệnh giúp chúng tôi đưa ra cách thức mổ.. Nghiên cứu này cao hơn so các nghiên cứu của các tác giả trên thế giới[2], [7].

Các đường mổ để tiếp cận khối u hậu nhãn cầu đã được nhiều tác giả trên thế giới báo cáo [1], [2], [5], [6]. Tai khoa Ngoại thần kinh bệnh viện $\mathrm{K}$, áp dụng phẩu thuật $\mathrm{u}$ hậu nhãn cầu gồm ba đường: đường mở nắp sọ trần ổ mắt, đường trực tiếp qua ổ mắt tự nhiên và mổ nội soi qua mũi để tiếp cận tổn thương thành trong hốc mắt. Một số trường hợp có thể phối hợp các đường mổ trên. Chọn lựa đường mổ được làm chủ yếu dựa trên vị trí, loại tổn thương, mức độ lan tỏa của u cũng như mục đích của phẫu thuật. Kết quả nghiên cứu này cho thấy: đường mở nắp sọ trần ổ mắt chiếm tỉ lệ cao nhất $70 \%$, tiếp theo là đường trực tiếp vào ổ mắt tự nhiên $20 \%$, đường mổ nội soi qua mũi để tiếp cận tổn thương thành trong hốc mắt $10 \%$. Đường mổ mở nắp sọ trần ồ mắt được ứng dụng rộng rãi nhất là với u vị trí khó đỉnh hốc mắt, xâm lấn nền sọ. Kết quả này phù hợp với các nghiên cứu [4], [6], [7].

Trong nghiên cứu của chúng tôi: các khối u màng não, sarcoma cơ vân thể bào thai, carcinom không sừng hóa xâm nhập là những u gặp nhiều nhất, chiếm tỉ lệ lần lượt là $23,3 \%$; $13,3 \% ; 10 \%$. Kết quả này cũng phù hợp với các nghiên cứu y học trên thế giới [2], [6]. Kết quả giải phẫu bệnh ở nhóm u khác do số lượng còn giới hạn, đa dạng về giải phẫu bệnh nển chưa cho phép nhận định về mối liên quan giải phẫu bệnh với các biến số lâm sàng khác. Tuy nhiên, ở trẻ em thường gặp nhất là glioma thần kinh thị, sarcoma cơ vân thể bào thai. Các u di căn hốc mắt, u màng não, u mạch,... thường gặp ở người lớn [6].

Điều trị u hậu nhãn cầu là điều trị đa mô thức bao gồm: phẫu thuật, xa trị, hóa chất, điều trị miễn dịch. Phẫu thuật vẫn là một phương pháp điều trị cơ bản nhằm lấy u tối đa và xác định chính xác độ mô học của khối u để đưa ra các chỉ định điều trị bổ trợ sao cho phù hợp. Trong một số trường hợp khi u ở những vị trí chức năng quan trọng không thể lấy hết u thì phẫu thuật mục tiêu của phẩu thuật là lấy bỏ tối đa nhằm tăng hiệu quả của các phương pháp điều trị bổ trợ tiếp sau.Trong nghiên cứu của chúng tôi, tỷ lệ phẫu thuật lấy hết u chiếm $46,7 \%$, lấy gần hết u $33,3 \%$, sinh thiết và giải ép chiếm $13,3 \%$, lấy một phần u chiếm $6,7 \%$. Tỷ lệ phẫu thuật lấy hết u thấp hơn trong khi lấy một phần u cao hơn so với nghiên cứu Margalit N (2007) [4], phẫu thuật lấy hết u và gần hết u cao hơn 
so nghiên cứu Park H] [5]. Phẫu thuật lấy một phần u là những trường hợp u xâm lấn vào những vùng chức năng quan trọng như dây thần kinh thị, động mạch mắt, nền sọ..., u có ranh giới không rõ ràng, nếu cố gắng lấy hết u sẽ gây thiếu hụt thần kinh nghiêm trọng, tử vong [6], [7].

Các biến chứng gặp nhiều nhất sau phẩu thuật là nhiễm trùng tại chỗ ( 4 ca mổ khoét bỏ nhãn cầu và lấy u) với tỷ lệ là 13,33\% đã được làm sạch rửa vết mổ tại chổ hốc mắt, điều trị nội khoa ổn định. Không có ca nào chảy máu, rò dịch não tủy, tràn khí hay mổ lại. Di chứng như sụp mi, liệt vận nhãn là triệu chứng hay gặp chiếm tỉ lệ lần lượt $10 \%$. Vì vậy, cần hiểu rõ về mặt hình ảnh học, cấu trúc giải phẫu, tiên lượng trước mổ và ứng dụng kính vi phẫu, hệ thống định vị, dao Cusa trong mổ giúp giảm các biến chứng, di chứng sau mổ. Có 3 trường hợp để lại di chứng trên do khối u to xâm lấn gây chèn ép lâu ngày. Những trường hợp sụp mi do cơ nâng mi trên bị vén trong quá trình phẫu thuật thường bệnh nhân sẽ hồi phục sau 3-6 tuần sau mổ. Có 07 trường hợp mất thị lực $(23,3 \%)$ trong đó 06 bệnh nhân có chỉ định khoét bỏ nhãn cầu, 01 bệnh nhân mất thị lực do u gây ra từ trước mổ. Các biến chứng và di chứng trong nghiên cứu thấp hơn so các nghiên cứu trên thế giới [4], [6],[7].

Thời gian khám lại ngắn nhất 03 tháng, dài nhất 48 tháng, trung bình $16,13 \pm 11,5$ tháng; Tỷ lệ chụp CT, MRI kiểm tra ở thời điểm khám lại sau 03 tháng chiếm $100 \%$ và hiện tại chiếm $26 / 30(86,7 \%)$. Trong đó, $8 / 30(26,7)$ bệnh nhân đã mất tập trung ở nhóm carcinoma do bệnh lý nguyên phát kết hợp và sarcoma, không điều trị bổ trợ hoặc điều trị không đủ liều xa hóa chất, thời gian sống ngắn nhất 3 tháng và dài nhất là 17 tháng. Nghiên cứu của chúng tôi cao hơn nghiên cứu Margalit N (2007) chiếm 2/41( $4,9 \%$ ) [4] và thấp hơn Markowski $](2014)$ 29,5\% [7]. U tồn dư, u lành tính, không tiến triển và không còn $u$, u lành tính lần lượt chiếm $30 \%$ và $13,3 \%$ tập trung ở nhóm u lành. Kết quả cao hơn nghiên cứu Markowski J (2014) [7]. U tiến triển, tái phát của chúng tôi có $6 / 30(20 \%)$ cao hơn Abuzayed $\mathrm{B}(2012)$ chiếm $15.2 \%$ [6], thấp hơn Markowski J(2014) 29,5\%[7]. Đặc biệt, có 01 trường hợp $(3,3 \%)$ là hình ảnh giả u do viêm mạn không đặc hiệu vô căn ở hốc mắt chúng tôi đã tiến hành phẫu thuật sinh thiết và giải ép lỗ thị,điều trị bởi corticoid nhưng những trường hợp này cần phân biệt bệnh lý lymphoma, tỷ lệ trển thấp hơn so nghiên cứu khác [2]. Nghiên cứu chúng tôi, có $15 / 30$ (50\%) không điều trị bổ trợ sau mổ, $7 / 30(23,3 \%)$ hóa xạ trị đồng thời và $7 / 30(23,3 \%)$ xạ trị. Như vậy việc láy u tối đa, đặc biệt $u$ ác tính giúp làm giảm kích thước khối u, làm giảm thể tích khối choán chỗ, tạo điều kiện thuận lợi cho điều trị tiếp theo (hóa trị, xạ trị). Tuy nhiên có 1 trường hợp u ác tính lymphoma $(3,4 \%)$ chỉ cần sinh thiết và điều trị bổ trợ hóa chất mục đích tăng hiệu quả tiêu diệt tế bào $u$, giảm thể tích khối u, giảm triệu chứng cơ năng, tăng chất lượng cuộc sống, tăng thời gian sống[2],[6],[7].

\section{KẾT LUẬN}

Tỷ lệ nam/nữ là 1,14/1; tuổi trung bình là $37,8 \pm 22,6$ (4 - 71 tuối). Triệu chứng lâm sàng thường hay gặp nhất là lî̀i mắt $(90 \%)$, đau mắt $(86,7 \%)$, giảm thị lực $(76,7 \%)$. Khối u lành tính $(43,4 \%)$, u ác tính $(56,7 \%)$; trong đó hay gặp nhất là u màng não $(23,3 \%)$, sarcoma cơ vần thể bào thai $(13,3 \%)$, carcinoma không sừng hóa xâm nhập $(10 \%)$. Kết quả lấy toàn bộ u và gần hết u là 46,7\% và 33,3\%. Không có trường hợp nào tử vong, chảy máu do phẫu thuật.

Kết quả khám lại hiện tại: Có $8 / 30$ (26,7\%) bệnh nhân tử vong, trung bình $9,0 \pm 4,3$ tháng, các loại giải phẫu bệnh (Carcinom không sừng hóa xâm nhập; Sarcoma (cơ vân thể hốc, xương, cơ vân thể bào thai, sụn trung mô, xơ bì lồi); Carcinom biểu bì nhày độ cao)). U tiến triển, tái phát: có $6 / 30(20 \%)$, trung bình $9,0 \pm 4,3$ tháng, các loại giải phẫu bệnh (Hemangiopericytome malin độ III, Sarcoma (cơ vân thể hốc, xương, cơ vân thể bào thai, xơ bì lồi), Carcinom không sừng hóa xâm nhập). Còn u tồn dư, u lành tính, không tiến triển: có $9 / 30$ (30\%), trung bình $15,67 \pm 12,7$ tháng, các loại giải phẫu bệnh (u màng não, loạn sản xơ xương, u mạch thể tĩnh mạch, giả u - viêm mạn). Không còn u, u lành tính: có $4 / 30(13,3 \%)$, trung bình $19,25 \pm 8,9$ tháng, các loại giải phấu bệnh (Swhannoma, u màng não).

\section{TÀI LIẸU THAM KHẢO}

1. Huỳnh Lê Phương (2012), "U hậu nhãn câu: Kinh nghiệm chẩn đoán và điếu trị phấu thuật". Y Học Thành́ Phố Hồ Chí Minh, 16(4), 273-281.

2. Darsaut TE, et al., (2001) Introductory overview of orbital tumorsNeurosurg Focus 10(5):1-9.

3. Ohtsuka K, et al., (2005) A review of 244 orbital tumors in Japanes patients during a 21 year period: origins and locations: Jpn Ophthalmol 49:49-55.

4. Margalit N, Ezer H, Fliss DM, Naftaliev E, Nossek E, Kesler Á (2007), "Orbital tumors treated using transcranial approaches: surgical technique and neuroophthalmogical results in 41 patients". Neurosurg Focus, 23(5), E11.

5. Park HJ, Yang SH, Kim IS, Sung JH (2008), " 
Surgical treatment of orbital tumors at a single institution". J Korean Neurosurg Soc, 44, 146- 150.

6. Abuzayed B, Kucukyuruk B, Tanriover N, Sanus GZ, Canbaz B, Akar Z, et al. (2012), "Transcranial superior orbitotomy for the treatment of intraorbital intraconal tumors: surgical technique and long-term results in single institute". Neurosurg Rev, 35(4), 573-582.

7. Markowski J, Jagosz-Kandziora E, Likus W, Pajak J, MrukwaKominek E, Paluch J, et al.
(2014), "Primary orbital tumors: a review of 122 cases during a 23-year period: a histo-clinical study in material from the ENT Department of the Medical University of Silesia". Med Sci Monit, 20, 988-994.

8. Boari N, Gagliardi F, Castellazzi P, Mortini P (2011), "Surgical treatment of orbital cavernomas: clinical and functional outcome in a series of 20 patients". Acta Neurochir (Wien), $153(3), 491-498$

\title{
KẾT HỢP NÚT TĨNH MACH CỬA VÀ TĨNH MACH GAN LÀM PHÌ ĐẠI GAN TRƯỚC PHẪU THUÂTT CẮT GAN LỚN: BÁO CÁO TRƯờNG HỢP
}

\author{
Lê Thanh Dũng ${ }^{1}$, Thân Văn Sỹ ${ }^{1}$, Ninh Viết Khải \\ Đào Xuân Hải ${ }^{1}$, Nguyễn Quang Nghĩa ${ }^{2}$
}

\section{TÓM TẮT}

Nút mạch đồng thời tĩnh mạch cửa và tĩnh mạch gan (LVD) được áp dụng rộng rãi trong thời gian gần đây do làm tắng đáng kể tốc độ và mức độ phì đại gan trước phấu thuât cắt gan lớn so với phướng pháp nút tĩnh mạch cửa (PVE) đơnn thuần, từ đó rút ngắn được thời gian chờ đợi phẫu thuật và giảm nguy cơ khổi u tiến triển. Chúng tôi báo cáo một trượng hợp được thực hiện LVD làm phì đại gan trước phẫu thuật cắt gan lớn do khối ung thư đường mật trong gan. Sau thủ thuật, bệnh nhân có tăng đáng kể thể tích gan còn lại theo dự kiến trong vòng 3 tuần. Phẫu thuật cắt gan phải mở rộng sau thời điểm nút mạch 4 tuần mà không có biến chứng suy gan sau phẫu thuât. Qua trường hợp lâm sàng này, chúng tôi nhận thấy LVD có hiệu quả cao trong việc làm tăng thể tích gan còn lại theo dự kiến (FLR) trước phẫu thuật cắt gan lớn.

Tư khoá: Nút tĩnh mạch cửa, nút tĩnh mạch gan, phẫu thuật cắt gan lớn, ung thư đường mật.

\section{SUMMARY}

SIMULTANEOUS PORTAL AND HEPATIC

\section{VEIN EMBOLIZATION BEFORE MAJOR}

LIVER RESECTION: A CASE REPORT

Simultaneous portal hepatic vein embolization (LVD) has been widely applied in recent years because of significantly increasing the rate and degree of liver hypertrophy in comparison with portal venous embolization (PVE) before major hepatectomy. So that, LVD brings the shortening waiting time for surgery and reducing the risk of tumor progression. We report a case where LVD was performed before major hepatectomy due to intrahepatic cholangiocarcinoma. The patient then had a significant

\footnotetext{
${ }^{1}$ Bệnh viện Hữu nghi Việt Đức

${ }^{2}$ Trung tâm Ghép Tạng - Bệnh viện Hữu nghị Việt Đức Chiu trách nhiệm chính: Thân Văn Sỹ

Email: sy.hmu0915@gmail.com

Ngày nhận bài: 10.8.2021

Ngày phản biện khoa học: 5.10 .2021

Ngày duyệt bài: 14.10.2021
}

increase in the future liver remnant (FLR) after 3 weeks. Major liver resection then was performed at 4 weeks after LVD without postoperative liver failure. From this clinical case, we found that LVD was highly effective in increasing FLR before major hepatectomy. This procedure could be a great alternative to PVE, especially in case of small initial FLR.

Keywords: Portal vein embolization, hepatic vein embolization, major liver resection, cholangiocarcinoma.

\section{I. ĐĂT VẤN ĐỀ}

Phẫu thuât cắt gan cho tới nay vẫn là phương pháp điều trị chính đối với các tổn thương ác tính tại gan. Nhược điểm chính của phương pháp này là nguy cơ suy gan sau phẫu thuật, đặc biệt ở những trường hợp cân cắt gan lớn mà thể tích gan không đủ [1]. Nút tĩnh mạch cửa (portal venous embolization - PVE) gây phì đại gan là kỹ thuật đã được áp dụng trên toàn thế giới từ nhiểu năm nay, góp phân mở rông chỉ định cắt gan và cải thiện kết quả sau phẫu thuâtt [2]. Mắc dù vậy, thủ thuật này đòi hỏi thời gian chờ đợi tương đối dài, thường phải sau 6 - 8 tuân. Hơn nữa, theo các báo cáo, có tới 30\% trường hợp bênh nhân sau PVE không thể phẫu thuât vì tăng thể tích gan còn lại theo dự kiến (future liver remnant - FLR) không đủ hoăc do khối u tiến triển [2].

Gần đây, trên thế giới đã và đang áp dụng phương pháp nút đồng thời tĩnh mạch cửa và tĩnh mạch gan (liver venous deprivation - LVD) thay thế cho PVE, cho thấy an toàn và tăng hiêu quả đáng kể về khả năng phì đai gan so với PVE [3], [4], [5]. Chúng tôi trình bày trường hợp lâm sàng được thực hiện nút đồng thời tĩnh mạch cửa và tĩnh mach gan nhằm mục đích gây phì đại gan trước phẩu thuât cắt gan lớn cùng một số tổng kết từ y văn. 